\title{
What's Wrong with the Diffusion of Innovation Theory?
}

The case of a complex and networked technology

\author{
Kalle Lyytinen ${ }^{1} \&$ Jan Damsgaard ${ }^{2}$
}

${ }^{I}$ Department of Computer Science and Information Systems, University of Jyväskylä

${ }^{2}$ Department of Computer Science, Aalborg Unviersity

Key words: diffusion of innovation theory, complex and networked technologies, electronic data interchange, EDI.

\begin{abstract}
This paper examines the usefulness of the diffusion of innovation research in developing theoretical accounts of the adoption of complex and networked IT solutions. We contrast six conjectures underlying DOI research with field data obtained from the study of the diffusion of EDI. Our analysis shows that DOI based analyses miss some important facets in the diffusion of complex technologies. We suggest that complex IT solutions should be understood as socially constructed and learning intensive artifacts, which can be adopted for varying reasons within volatile diffusion arenas. Therefore DOI researchers should carefully recognize the complex, networked, and learning intensive features of technology; understand the role of institutional regimes, focus on process features (including histories) and key players in the diffusion arena, develop multi-layered theories that factor out mappings between different layers and locales, use multiple perspectives including political models, institutional models and theories of team behavior, and apply varying time scales while crafting accounts of what happened and why. In general the paper calls for a need to develop DOI theories at the site by using multiple levels of analysis.
\end{abstract}

The original version of this chapter was revised: The copyright line was incorrect. This has been corrected. The Erratum to this chapter is available at DOI: 10.1007/978-0-387-35404-0_19 


\section{INTRODUCTION}

The slow, and often unexpectedly painful adoption of information technology (IT) innovations (Attewell 1992; Lyytinen 1991) has lead scholars and practioners to seek to understand, manage and predict its diffusion.

One popular account to explain and predict rates of IT innovation adoptions is diffusion of innovation theory (DOI) as propagated by Rogers (Rogers 1995). The DOI tradition draws upon rational theories of organizational life adopted from economics, sociology and communication theory. It develops predictive accounts of the diffusion phenomenon that supposedly helps technology implementors advance the diffusion of selected technologies. DOI theory has gained wide popularity in the IT field, for example Prescott and Conger (Prescott and Conger 1995) found over 70 IT articles published in IT outlets between 1984-1994 that relied on DOI theory.

Overall, the DOI tradition has sought to explain individual adoption decisions or intentions to adopt. These decisions concern well-defined innovations (like TV sets or the use of a pesticide among farmers) and the adoption population is relatively homogeneous and has well defined boundaries. A host of factors including the availability of information concerning technology (like relative advantage, compatibility etc), adopters' properties (like past experiences), characteristics of the social system (like management support, social norms, availability of change agents), and the communication process (through which media, how often) explains the adoption decisions. Scholars of IT diffusion have been quick to apply the widespread DOI theory to IT but few have carefully analyzed whether it is justifiable to extend the DOI vehicle to explain the diffusion of IT innovations too?

This paper questions the usefulness and applicability of DOI to explain the diffusion of a complex, standard-based and networked information technology. For this purpose we extract six conjectures from DOI and contrast them with data of the diffusion of Electronic Data Interchange (EDI) in three social contexts - Hong Kong, Finland and Denmark. By contrasting

${ }^{7}$ Similar critical voices have been raised recently against a too simplistic and fixed view of IT. For example, (Ciborra 1996) discusses "drifting technologies", and warns about a too static view of technology. (Grudin 1988) shows how social factors are inherently crucial in understanding the success or failure of the use of groupware technologies - not alone their static features. And (Hanseth 1996) explains IT diffusion as simultaneousness shaped as an infrastructure. 
theory and field study data we can analyze the usefulness of the DOI theory to explain actual observed diffusion behaviors. The conjectures also invite further research that can complement the shortcomings of DOI theory.

This paper proceeds as follows. First we discuss DOI models and their locus. In section three we present and describe EDI technology from a diffusion point of view. In section four we distill six conjectures from DOI theory and test them using a Popperian approach of refuting the conjectures by providing one or more counter examples for each. Finally we discuss the implications of our analysis and sketch a path for a way forward to establish better theoretical accounts of IT diffusion.

\section{DIFFUSION OF COMPLEX AND NETWORKED TECHNOLOGIES: THE CASE OF EDI}

Complex and networked technologies include electrical supply systems, chemical industries and transportation systems. These systems contain messy, complex problem solving elements. They are both socially constructed and society shaping (Hughes 1987). They include physical artifacts, and the organizations that use and manufacture them, but they also relevant legislative and regulative bodies and scientific communities. Alignment of multiple interests is required for social construction of the innovation's significance, the negotiation of standards, and the legitimation of the acceptable uses of the innovation. These systems are difficult to control and manage due to their messy institutional character, broad scope and longevity.

IS research dealing with the diffusion of networked technologies covers e.g. personal computing (Heikkilä 1995), airline reservation systems (McKenny 1995), collaborative computing (Star and Ruhleder 1996), NII (King and Kraemer 1995) and EDI. EDI is the focus technology of this paper and the following points characterize EDI as complex standard-based and networked technology.

1. EDI is inter-organizational in nature;

2. EDI links electronically organizations thus requiring considerable alignment of organizational procedures and policies

3. EDI is a complex, innovative and abstract innovation that requires considerable skills and know-how to implement and operate (Webster 1995)

4. EDI relies on an advanced telecommunication infrastructure which creates a large set of dependencies with other components of the technological system 
5. EDI implementations are often built on third party operated Value Added Networks or Internet Service Providers which complicate the promotion of EDI and create additional dependencies in the technological system

6. EDI is based on standards (Damsgaard and Truex 2000). Therefore EDI uses create a high degree of organizational interdependence (Hørlück 1994), and necessitates institutional regulation

7. EDI requires a considerable user mass to be efficiently deployed

From a diffusion of innovation viewpoint EDI has several features that characterize complex and networked technologies. First, points (1), (2), (3) and (4) imply that its adoption creates path dependencies with earlier innovations. Second, points (1) and (7) suggest that the decision to invest in EDI is not solely dependent on singular adopters, but on "herd" effects of having sufficiently many simultaneous adoption decisions. Third, points (1), (4) and (6) suggest that the success of EDI adoption does not solely depend on individual adopters' goals and desires, but as well on the effectiveness of broader institutional and regulatory regimes. These regimes can employ measures to reduce innovation ambiguity and uncertainty. Fourth, points (3) and (6) imply that due to EDI's complexity it has high learning barriers (Attewell 1992). Fifth, points (1), (2), (4) and (5) blur the distinction between technical and administrative innovations so much heralded in the DOI research (Damanpour and Evan 1984). Sixth, points (1) and (2) raise the issue of how the unit of analysis should be defined in the study of the diffusion process. For example, new forms of customer-supplier relationships can be implemented along all parts of the value system, which easily expands the analysis to industries, and even whole economies, or communities of traders (Wrigley, Wagenaar, and Clarke 1994).

\section{SIX CONJECTURES OF DIFFUSION THEORY RECONSIDERED}

Rogers (1995) defines DOI as the process "by which an innovation is communicated through certain channels over time among the members of the social system". A typical model consists of sequential adoption and implementation stages. These stages help predict innovation of diffusion over time and space (Lyytinen 1991). DOI explains diffusion rates by the characteristics of the innovation, and the surrounding social system (Wolfe 1994). Factors that have been found to influence diffusion rates include: adopter characteristics, the social network they belong to, the communication process, the characteristics of the promoters, and the 
innovation attributes including triability, relative advantage, compatibility, observability, and complexity. Variations in research constructs are usually restricted to the choice of adopting units, and to the number of variables included in the model. The models are not very specific about the items of diffusion, and seldom question whether the studied technology makes a difference (Monteiro and Hanseth 1995; Prescott and Conger 1995; Wolfe 1994).

The key question we ask in this paper is the following: are DOI theory's concerns in explaining an individual adopter's behavior with respect to a static technological artifact (Mahajan, Muller, and Bass 1990; Rogers 1995) in a homogeneous population sufficient to understand EDI adoption? Will DOI theory based analysis of EDI diffusion miss some important facets? We suspect that this is the case based on our observations from three diffusion studies (Damsgaard 1996; Damsgaard 1997; Damsgaard and Lyytinen 1997; Damsgaard and Lyytinen 1998). To demonstrate we shall examine six conjectures $^{8}$ that underlie the DOI theory and compare these conjectures with our field data findings. We thus follow a Popperian advice and seek to refute DOI theory predictions by using a counterexample (Popper 1968) thus questioning DOI theory's power to explain the diffusion of networked and complex technologies.

The six conjectures of the DOI model can be summarized as follows (Mahajan, Muller, and Bass 1990; Premkumar, Ramamurthy, and Nilakanta 1994; Prescott and Conger 1995; Rogers 1995; Tornatzky and Klein 1982): An innovation (technology) has separate, distinguishable and objective features, which are easily recognizable by interested parties (1). The technology moves in a discrete package from an independent innovator to the adopter through a constant social "ether" called here a diffusion arena (2). The adopter's choice to adopt forms an atomic, isolated decision, which is shaped by the push and pull factors (3). The decision to adopt follows a rational calculus that is based on observed technological characteristics, and other relevant information made available to the adopter through communication channels (4). The diffusion process evolves through distinct stages, which are determined by the push and pull forces and are distinguishable by changes in the adoption rate (5). Finally, the diffusion process has neither feedback, nor any "effective" history (6). The conjectures are consolidated in table 1 .

${ }^{8} \mathrm{We}$ call them conjectures as they are mostly informed guesses used to derive conclusions. 
Table 1. DOI theory conjectures and supporting literature

\begin{tabular}{|c|c|c|}
\hline & Conjecture & References in support \\
\hline 1 & $\begin{array}{l}\text { Technologies are discrete packages developed } \\
\text { by independent and neutral innovators; }\end{array}$ & $\begin{array}{l}\text { (Hai 1998; Premkumar, } \\
\text { Ramamurthy, and Nilakanta } \\
\text { 1994; Rogers 1995; Tornatzky } \\
\text { and Klein 1982) }\end{array}$ \\
\hline 2 & $\begin{array}{l}\text { Technologies diffuse in a homogenous fixed } \\
\text { social ether called diffusion arena, which is } \\
\text { separate from the innovation locale; }\end{array}$ & $\begin{array}{l}\text { (Mahajan, Muller, and Bass } \\
\text { 1990) }\end{array}$ \\
\hline 3 & $\begin{array}{l}\text { Diffusion rate is a function of push and pull } \\
\text { forces }\end{array}$ & (Thirtle and Ruttan 1987) \\
\hline 3.1 & $\begin{array}{l}\text { Push factors include features of technology, and } \\
\text { channels of communication, }\end{array}$ & $\begin{array}{l}\text { (Mahajan, Muller, and Bass 1990; } \\
\text { Rogers 1995) }\end{array}$ \\
\hline 3.2 & Pull is determined by adopter's rational choices; & (Rogers 1995) \\
\hline 4 & $\begin{array}{l}\text { Adoption decisions are dependent on available } \\
\text { information, preference functions and adopter's } \\
\text { properties; }\end{array}$ & (Rogers 1995) \\
\hline 5 & $\begin{array}{l}\text { Diffusion traverses through distinct stages, } \\
\text { which exhibit little or no feedback; and; }\end{array}$ & $\begin{array}{l}\text { (Nolan 1973; Nolan 1979; Rogers } \\
\text { 1995) }\end{array}$ \\
\hline 6 & $\begin{array}{l}\text { Time scales are relatively short and the } \\
\text { diffusion history is not important. }\end{array}$ & (Rogers 1995) \\
\hline
\end{tabular}

\subsection{Technologies are not discrete packages}

DOI research associates an innovation with distinct and measurable features (Hai 1998; Premkumar, Ramamurthy, and Nilakanta 1994; Rogers 1995; Tornatzky and Klein 1982). With this sort of definition, several difficulties emerge. First, it is not clear whether the list is complete and covers all features that affect adopter's behavior. For example, why technical elegance or style does not appear in the lists though studies in the history of technology demonstrate the contrary (Hughes 1987). Second, why all technological innovations should be characterized with the same set of attributes? For example can EDI be characterized with the same set of attributes like a Television? Third, what roles play these different

9 (Tornatzky and Klein 1982) list the following ten attributes: 1) compatibility; 2) relative advantage; 3) complexity; 4) cost; 5) communicability; 6) divisibility; 7) profitability; 8) social approval; 9) triability; and 10) observability. Whereas (Premkumar, Ramamurthy, and Nilakanta 1994) used the following subset for studying EDI diffusion: 1) compatibility, 2) relative advantage, 3) costs, 4) communicability, while (Hai 1998) used another set of six attributes: 1) relative advantage, 2) compatibility, 3) complexity, 4) triability, 5) observability, and 6) risk. 
characteristics at different stages of diffusion? For example, compatibility may mean different things for the late and early adopters. Fourth, the assumption ignores the socially constructed nature of large technological systems. All studies demonstrate that such innovations are socially constructed, learning intensive, complex and networked (Pinch and Bijker 1987).

Complex technological systems have "interpretive flexibility" i.e. their significance varies from one context to another and from one time point to another (Karsten 1995; Orlikowski and Gash 1993; Pinch and Bijker 1987). Consequently, groups, organizations, and industries construct the meaning of the technology differently. Local culture, economic structure and the supporting infrastructure (education system, government policies) shape these constructs. This observation was confirmed in our studies. The ideas about what EDI was and meant and what connotations it carried varied radically in different sites and affected the adoption decisions (Damsgaard 1996).

IT technologies are learning intensive in that resources have to be continuously poured into their maintenance and modification (Heikkilä 1995). This changes the innovation over time. For example, how an organization integrates its internal systems with EDI is not a simple task and demands continuous learning to align organizational processes and structures and technologies. This feature was also demonstrated by the long time spans required to make EDI fully operational. Furthermore, integrated technologies co-evolved and had to be transformed. In one EDI adoption process a shipping line initially pushed a container terminal to adopt EDI. This application, however, required intensive learning from both parties, and obligated the container terminal to wholly rethink its organizational processes. What started as an straight forward data link that carried simple announcements of shipping information was gradually transformed into a highly complex and integrated IT application (Damsgaard and Lyytinen 1997).

In all cases we studied the adoption was not a simple decision of how to exploit EDI as a stand-alone technical solution. Instead it formed a part of a complex interplay of multiple technological systems (IT applications, telecommunication services, standards), partners' communication tactics, backward compatibility with other technological systems ${ }^{10}$, demonstrated benefits, and power play. In EDI adoptions local power play and institutional facilitation were the most common features that were considered during all

${ }^{10}$ And not compatibility with adopters' understanding and needs as in DOI research, (Rogers 1995) 
adoption decisions. Thus, the herd effect rather than any specific technological characteristic (tangible or in-tangible) led to the adoption decision (Bouchard 1993; O'Callaghan and Turner 1995).

\subsection{Technologies do not diffuse in a homogenous and fixed social ether}

In the DOI theory interactions between technology suppliers and adopters are expected to happen in a relatively homogeneous space. For example, the Bass model expects to estimate three diffusion parameters ${ }^{11}$ similar to the diffusion of entropy in an ideal gas (Mahajan, Muller, and Bass 1990). The conjecture is that the technology diffuses in this ether through the influences of these three "forces". With complex technologies like EDI, however, the diffusion arenas are neither fixed nor homogeneous. Instead, institutional arrangements, the business context and technological and economic constraints reshape these arenas. Therefore, in analyzing EDI diffusion we found it necessary to employ institutional concepts to dynamically draw the borders of the diffusion space to understand what the studied processes were like. The institutional perspective helps focus on institutional measures and regimes that are involved in defining the scope and mandate for the diffusion process. Potent institutional changes can radically affect the speed and course of any diffusion process by redrawing its boundaries, redefining involved entities and changing incentives. Consider for example the amazing diversity of diffusion behaviors we observed in retail sectors in Hong Kong, Denmark and Finland, though the technologies and the adoption rationales were similar (Damsgaard 1997; Damsgaard and Lyytinen 1997; Damsgaard and Lyytinen 1998). In Hong Kong EDI triggered institutional intervention, in Finland it caused collaboration and establishment of an institutional arrangement to support diffusion, while in Denmark EDI was launched as a weapon in the ongoing struggle between two large retail chains. To a large extent these differences were due to variations in the institutional scopes and mandates.

11 These are coefficient of external influence, the coefficient of internal influence and the market potential. 


\subsection{The diffusion rate is not solely a function of push and pull forces}

The DOI theory integrates two supplementary modes of explanation: the supply-push and the demand-pull theories (King and others 1994; Zmud 1984). Supply-push theories reckon that specific features of the innovation cause the EDI diffusion like its functionality, or the standards that enable its use. EDI is thus portrayed as a technological fix for organizations' supplychain problems (Thirtle and Ruttan 1987). The demand-pull theories explain EDI diffusion by a growing demand for organizational coordination. Organizations need to improve their internal operations, and change their market positions by applying technical knowledge (Bensaou 1996; Porter 1985). Several IS studies have considered both forces simultaneously (Bouchard 1993; Delhaye and Lobet-Maris 1995; Premkumar, Ramamurthy, and Nilakanta 1994). Unfortunately the predictive power of the theory has been low and the results confounding (Hai 1998; Prescott and Conger 1995). For example the variance explained using the DOI theory constructs has constantly remained below 40 per cent. Our studies confirm that these "forces" did not form necessary and sufficient conditions for an adoption. Instead many adoptions could be explained whether the adopting organizations followed power dominant or consensus-seeking strategies, and what type of history they had with their EDI partners (Damsgaard and Lyytinen 1997).

\subsubsection{Push factors include features of technology, and channels of communication}

The push forces frame the adoption decision as a rational choice problem between an old and a new technology. The main source of decision information is mass media and word of mouth i.e. different communication channels (Rogers 1995). Our data shows a different reality. The push for EDI did not happen through the mass media or peer networks. Instead EDI was pushed by powerful actors (gatekeepers) - e.g. hubs, industry associations, or the government (Damsgaard and Lyytinen 1997). These entities used symbolic or real measures to push the technology involving demonstrations of vested power and/or biased communications. In contrast, many organizations that were well informed of EDI did not adopt, or were not able to adopt EDI due to scarce resources, power structures or the lack of skills and competence. 


\subsubsection{Pull is determined by adopter's rationale choices}

In DOI theory adopter follows the ethos of "homo economicus": the choice is based on a careful analysis of the technology features. Yet, in real life EDI adoptions were not celebrations of rationality - organizations seldom followed what their rational analysis suggested. Few organizations performed any cost/benefit analyses of the adoption (Bjørn-Andersen and Krcmar 1995). A typical decision would be the following: a container terminal was pushed by its customer to implement EDI, though the terminal knew that it would not benefit from adopting. EDI increased work and complicated the technological base. Yet, the "decision" was made as there were no alternatives i.e. the adoption was obligatory within a certain time period, if the container terminal wanted to remain in business ${ }^{12}$. Therefore organizations chose between the lesser evil of adopting EDI thus following the well-known slogan: "EDI" or "DIE" (Delhaye and Lobet-Maris 1995; Webster 1995).

\subsection{Choices are not functions of available information, preference functions and adopter's properties}

In the DOI theory, adoption decisions are functions of available information, preference functions, risk and the adopter's properties ${ }^{13}$. In EDI adoptions the choice parameters, however, fluctuated over time and over diffusion arenas in ways, which could not be derived from DOI theory. Consider the case of attempting to establish a strategic EDI network in Hong Kong (Damsgaard and Lyytinen 1997). The network sought to change the information exchange patterns in a large portion of the sea cargo transportation sector and adjoining sectors in Hong Kong. Many actors did not support the creation of the network but once it was assembled several fence sitters were afraid of loosing important business opportunities if they did not join i.e. their strategy was not to maximize their benefits, but to avoid losses. The choice was not related to available information about the technology but to business strategy. Choice parameters were also quite different in other situations. The garment industry in Hong Kong openly announced that it was not doing anything in regard to EDI before the

12 These issues could only be observed by examining the broader institutional context and how it redrew the boundaries.

${ }^{13}$ (Rogers 1995) observes at the same time that early adopters differ from late adopters along these properties (i.e. knowledge, skill and risk taking behavior). 
territory-wide EDI initiative Tradelink was operational. Instead in Hong Kong's retail sector the intervention of the article numbering association radically reshaped the diffusion arena. This has significantly lowered the entry barriers in the whole retail sector. All these illustrations assert the same fact: choice factors fluctuate over time and social spaces.

Sometimes adoption factors can be locally unique. Consider the following: the high rentals for retail premises formed the prime motivating factor for the association of retailers and the article numbering association to initiate EDI in Hong Kong (McKendrick 1993):

"The biggest single threat to the retail industry and hence the supply chain in Hong Kong is escalating rentals imposed/demanded by Hong Kong's landlords. For some, if not most retail sectors, the answer is not that simple as passing these costs on to the customers in higher retail prices. The industry has to become more efficient: Retailers, Manufacturers, and Suppliers have to work together to take costs out of the supply chain"

\subsection{Diffusion does not necessarily traverse through distinct stages, which exhibit no feedback}

In the DOI theory, the diffusion curve is divided into stages (Nolan 1973; Nolan 1979; Rogers 1995). Our observations suggest that complex technologies will not diffuse in sequential stages. Many times it was not clear what these stages would mean in relation to the observed behavior. In some situations adoptions took place in dyadic relationships where it was difficult to see what the notion of an early adoption would mean. Sometimes adoptions were effected by moves in one industry or across industries, and all adopters were early innovators by Rogers' terms though they did not share their characteristics. In some situations the adoptions sought to cover the whole trading community (what would early and late mean in this case?). There were also reversed processes where the innovation was dropped or its' use retarded, so strong outside competitors could not take advantage of its presence. We had also contradictory behaviors: we had "laggards" which were more visionary in their uses of EDI than those who Rogers calls "innovators" 14.

We also observed also that stages could be layered: the initiation stage would last for 15 years for some diffusion contexts. At the same time

${ }^{14}$ This behavior was explained many times as a strategic choice: resources that were poured into building the first EDI implementation were magnitudes larger and much more risky. Many companies were simply waiting to find out what technology and standard would "win" before making their decision. In this way the companies sought to lower risks, save resources, and enjoy network externalities. 
the overall diffusion in other types of solutions had well gone beyond the early adoption. The stages were also embedded, i.e. one diffusion arena could turn into another one. Organizations could for example move from a dyadic adoption to an industry level adoption, and vice versa (i.e. bilateral optimizations of industry level adoptions). This could result in stepwise adoption curves (rather than sigmoid). This shows that the penetration level and the diffusion rate between countries, industry sectors and organizations are highly interdependent and not independent as assumed in the DOI theory.

We observed also feedback loops. The local history, information available from the earlier trials and the dynamics of the diffusion arena all affected the shape of the diffusion curve. The case in point here is Tradelink, (Damsgaard 1996), which carried throughout its history the stigma from its earlier failures. This in turn leads to continued failures and inability to move beyond the initiation stage.

...TradeLink, I think, is the second or third attempt in Hong Kong. Hong Kong has had a number of false starts with the same people involved. So every time they carry a sense of mistrust and disbelief from previous generations. So there are quite a few psychological barriers... (Industry representative, 1995, reported in (Damsgaard 1996))

\subsection{Time scales are not necessarily short and the history of decisions is not unimportant}

In DOI theory used time scales are normally relatively short and the mechanisms that drives the diffusion do not change over time. Time scales range from few months to some years, and once the important technological and organizational characteristics have been determined they remain stable over time, so that the diffusion process is relatively deterministic. Moreover the past decision history is not regarded important. EDI, however, exhibits path dependencies, because it forms an add-on to the existing technology base. Accordingly many diffusion behaviors had to be traced relatively long back into the history of the social context. Consider the Finnish experiences with EDI adoption (Damsgaard and Lyytinen 1998). Finns moved into EDI very early due to the long and well-established history of industry wide cooperation in uses of IT in several sectors (especially banking and retail). These sectors developed and adopted pre-UN/EDIFACT solutions for interorganizational data interchange. This created a need to collaborate to establish and maintain national Finnish standards for those sectors. Now 
Finns have to decide what to do. Either to dissolve the national proprietary standard and migrate to EDIFACT thereby throwing away major investments and jeopardizing existing local networks of collaboration. Or to stay with the proprietary Finnish standard that does the job nicely, but for national communication only. Hence, in order to understand EDI diffusion in Finland, it is necessary to trace back historical events until mid 1970's that led to the prevailing consensus seeking strategies but also to the dilemma of today.

Another obvious example of the power of past decisions is that of driving on the left side or the right side of the road (Kindleberger 1983). Most people would agree that choosing one side only is far superior (either side) than leaving it to mutual adjustment. However traditions, sunk costs as well as the investments necessary to change the existing infrastructure and habits, and the no doubt heated discussions involved in making a choice makes it a discussion no one will engage in. The same principle applies for complex and networked technologies.

The diffusion trajectory is also contingent on feedback mechanisms, which form a universal property of any diffusion process. Therefore diachronic analyses should form an integrated part of a diffusion study. Feedback systems can operate on different time scales with different innovations. This is nicely exemplified by the choice that Finnish companies face when adopting EDI. Should they choose the Finnish proprietary standard, which is extensively applied and simple to use? Or should they choose the UN/EDIFACT that is more complicated and constantly changing, but allows them to communicate internationally? (Damsgaard and Truex 2000) Their choices will again have wide impact on what the trade associations will recommend and what standard the industry as such will choose in the future (Arthur 1989).

\section{DISCUSSION AND CONCLUSIONS}

The DOI research has had a considerable positive impact on IS research. Our analysis points out, however, that it falls short of some theoretical constructs that help address how complex networked technologies can and will diffuse $^{15}$. Several basic premises of the DOI theory therefore need a careful reconsideration in the context of the networked and complex technologies. In particular, DOI theory does not offer adequate constructs to deal with

${ }^{15}$ We agree with Prescott's and Conger's conclusions when they note "DOI theory appears to be more applicable to IT applications, which have intraorganizational locus of impact" (Prescott and Conger 1995). 
collective adoption behaviors (including the critical role of standards, critical mass, network externalities, sunk costs, path dependence etc.). The DOI researchers should be careful in analyzing the impact of the nature and meaning of the technology, the role of institutional policies and regimes, the impact of the industrial policies and strategies, and the importance of the installed base and learning inertia. Due to the inattention to these features DOI models could not explain EDI adoptions. Instead, we observed that the diffusion "factors" had to be changed radically due to the complex and networked nature of the technology, i.e. by expanding the scope and time scale of the diffusion study.

The analysis leaves us with a "theoretical" gap between the current main stream and our field study findings. Generally, DOI researchers have traded simplicity and generalizibility against accuracy by using simple metaphors of "forces" and "diffusion rates". Consequently, DOI models resemble physical models of thermodynamics. Instead, our studies taught us to trade both simplicity and generalizability against accuracy. Consequently the models were process based, contextual and non-deterministic, and could identify necessary conditions for an adoption (Downs and Mohr 1976; Markus and Robey 1988).

As a step forward it is necessary to consider the following issues while studying complex networked technologies:

- Seek to understand the local complex, networked, and learning intensive features of technology.

- Seek to understand the critical role of market making and institutional structures in shaping the diffusion arena.

- Focus on critical process features and all key players in the diffusion arena.

- Develop multi-layered theories of diffusion that factor out mappings between different layers and locales.

- Use alternative theoretical perspectives that help extend analysis beyond questions of efficient choice. Good candidates include political models, institutional models and theories of team behavior in conflictcooperative games (Wolfe 1994).

- Recognize the need for varying time scales when seeking to account for what happened and why.

- Develop theories at the site and with multiple levels of analysis.

We believe that armed with such theoretical guidelines DOI researchers will have a higher likelihood of providing faithful accounts of the diffusion of complex and networked innovations. 


\section{ACKNOWLEDGEMENTS}

The first author presented an earlier version of this paper at the IFIP 8.6. Working Conference in Oslo, October 1995 with the title" Diffusion theory: Complex technologies, institutional arenas and time: Notes of diffusion research". The paper has also been presented in Case Western Reserve University (February 1997) and City University of Hong Kong (September 1997). We are in particular thankful for comments obtained from Richard Boland, Fred Callopy, Michael Ginzberg, Robert Davison, Carsten Sørensen, Ivan Aaen and John L. King. Thanks go also to Georgia State University in which the first author worked as a G. E. Smith Visiting Professor while writing the article. This research was in part supported by the Danish Research Agency, grant number 9900102.

\section{REFERENCES}

Arthur, W. B. "Competing Technologies, Increasing Returns and Lock-in by historical events." Economic Journal, Volume 99, 1989, pp. 116-131.

Attewell, P. "Technology diffusion and organizational learning: The case of business computing." Organization Science, Volume 3, Number 1, 1992, pp. 1-19.

Bensaou. "7-Eleven Japan: Creating the Virtual Corporation." In Proceedings of the 4th European Conference on Information Systems, ed. J. Dias Coelho, Tawfik Jelassi, Wolfgang Koning, Helmut Krcmar, and Markku Saaksjarvi, 1275-1307. Lisbon, Portugal: Litografia Amorim, 1996.

Bjørn-Andersen, N., and Krcmar, H. "Looking Back - A cross-analysis of 14 EDI cases." In EDI in Europe: How It Works in Practice, ed. Helmut Krcmar, Niels Bjørn-Andersen, and Ramon O'Callaghan, 299-325. Chichester: John Wiley \& Sons Ltd., 1995.

Bouchard, L. "Decision Criteria in the Adoption of EDI." In Proceedings of the 14th International Conference on Information Systems, 365-376. Orlando, Florida, 1993.

Ciborra, C. U., ed. Groupware \& Teamwork, Wiley Series in Information Systems. Chichester: John Wiley \& Sons, 1996.

Damanpour, F., and Evan, W. "Organizational Innovation and performance: the problem of 'organizational lag'." Administrative Science Quarterly, Volume 29, 1984, pp. 392-409.

Damsgaard, J. The Diffusion of Electronic Data Interchange: An Institutional and Organizational Analysis of Alternative Diffusion Patterns. Aalborg: Ph.D. Thesis, R-962041, Department of Computer Science, Aalborg University, 1996.

Damsgaard, J. "The Danish EDI Bandwagon Gaining Momentum." In Proceedings of the 30th Hawaii International Conference on Systems Science, Maui, Hawaii, ed. R. H. Sprague, IV, 31-41. Wailea: IEEE Computer Society Press, 1997.

Damsgaard, J., and Lyytinen, K. "Hong Kong's EDI Bandwagon. Derailed or on the right track?" In Facilitating Technology Transfer Through Partnership: Learning from Practice and Research., ed. Tom McMaster, Enid Mumford, E. Burton Swanson, Brian Warboys, and David Wastell, 39-63. London: Chapman and Hall, 1997. 
Damsgaard, J., and Lyytinen, K. "Contours of Electronic Data Interchange in Finland: Overcoming technological barriers and collaborating to make it happen." The Journal of Strategic Information Systems, Volume 7, 1998, pp. 275-297.

Damsgaard, J., and Truex, D. "The Procrustean Bed of Standards. Binary relations and the limits of EDI standards." European Journal of Information Systems, Volume 9, Number 3, 2000, pp. 173-188.

Delhaye, R., and Lobet-Maris, C. "EDI Adoption and Standard Choice: A Conceptual Model." In Proceedings of the 3rd European Conference on Information Systems, ed. G. Doukidis, B. Galliers, T. Jelassi, and F. Land, 165-182. Athens, Greece: Print Xpress, 1995.

Downs, G. W., and Mohr, L. B. "Conceptual Issues in the study of innovation." Administrative Science Quarterly, Volume 21, 1976, pp. 700-714.

Grudin, J. "Why CSCW applications fail: Problems in the design and evaluation of organizational interfaces." Office, Technology and People, Volume 4, Number 3, 1988, pp. 245-264.

Hai, T. H. Organizational Predisposition toward and Information Technology Innovation: The Roles of Three Theoretical Perspectives in the Case of Financial Electronic Data Interchange. Singapore: Department of Computer Science and Information Systems, National University of Singapore,, 1998. Ph.D Thesis.

Hanseth, O. Information Technology as Infrastructure. Gothenburg: Ph.D. Thesis, Report 10, Department of Informatics, Gothenburg University, 1996.

Heikkilä, J. The Diffusion of a Learning Intensive Technology Into Organizations: The Case of Personal Computing: Ph.D. Thesis, A-104, Helsinki School of Economics and Business Administration, 1995.

Hughes, T. "The Evolution of Large Technological Systems." In The Social Construction of Technological Systems, ed. W. Bijker, T. Hughes, and T. Pinch, 51-82. Cambridge, Mass.: The MIT Press, 1987.

Hørlück, J. "The Pragmatics of EDI: The Use of EDI will unify Business procedures." International Journal of Information Management, Volume 14, Number 5, 1994, pp. 330343.

Karsten, H. "'It's like everyone working around the same desk": Organisational Readings of Lotus Notes." Scandinavian Journal of Information Systems, Volume 7, Number 1, 1995, pp. 3-32.

Kindleberger, C. P. "Standards as Public, Collective and Private Goods." Kyklos International Review for Social Sciences, Volume 36, Number 3, 1983, pp. 377-396.

King, J. L., Gurbaxani, V., Kraemer, K. L., McFarlan, F. W., Raman, K. S., and Yap, C. S. "Institutional Factors in Information Technology Innovation." Information Systems Research, Volume 5, Number 2, 1994, pp. 139-169.

King, J. L., and Kraemer, K. L. "Information Infrastructure, national policy and global competitiveness." Information Infrastructure and Policy, Volume 1, Number 1, 1995, pp. $1-24$.

Lyytinen, K. "Penetration of information technology in organizations. A comparative study using stage models and transaction costs." Scandinavian Journal of Information Systems, Volume 3, 1991, pp. 87-109.

Mahajan, V., Muller, E., and Bass, F. M. "New Products Diffusion Models in Marketing: A review and Directions for Research." Journal of Marketing, Volume 54, 1990, pp. 1-26. 
Markus, M. L., and Robey, D. "Information Technology and Organizational change: Causal Structure in Theory and Research." Management Science, Volume 34, Number 5, 1988, pp. 583-598.

McKendrick, A. A Report on Electronic Data Interchange by the EDI Working Party of the Hong Kong Retail Management Association. Hong Kong: Hong Kong Retail Management Association, 1993.

McKenny, J. Waves of change. Boston: Harvard Business School Press, 1995.

Monteiro, E., and Hanseth, O. "Social Shaping of Information Infrastructure: On Being Specific about the Technology." In Proceedings of the IFIP WG 8.2 working Conference on Information Technology and Changes in Organizational Work, ed. Wanda J. Orlikowski, Geoff Walsham, and Janice I. DeGross, 325-343: Chapman and Hall, 1995.

Nolan, R. L. "Managing the Computer Resource: A Stage Hypothesis." Communications of the $A C M$, Volume 16, Number 7, 1973, pp. 399-405.

Nolan, R. L. "Managing the crisis in data processing." Harvard Business Review, Volume March-April, 1979, pp. 115-126.

O'Callaghan, R., and Turner, J. A. "Electronic Data Interchange - Concepts and Issues." In EDI in Europe: How It Works in Practice, ed. Helmut Krcmar, Niels Bjørn-Andersen, and Ramon O'Callaghan, 1-19. Chichester, New York, Brisbane, Toronto, Singapore: John Wiley \& Sons Ltd., 1995.

Orlikowski, W. J., and Gash, D. C. Technological Frames: Making Sense of Information Technology in Organizations. : Working paper \#3627-93. Alfred P. Sloan School of Management, MIT, 1993.

Pinch, T., and Bijker, W. "The Social Construction of Facts and Artifacts: or how the sociology of science and the sociology of technology might benefit each other." In The Social Construction of Technological Systems, ed. W. Bijker, T. Hughes, and T. Pinch, 1750. Cambrigde, Mass.: The MIT Press, 1987.

Popper, K. Conjectures and Refutations. New York: Harper and Row, 1968.

Porter, M. E. Competitive Advantage: Creating and Sustaining Superior Performance. New York: The Free Press, 1985.

Premkumar, G., Ramamurthy, K., and Nilakanta, S. "Implementation of Electronic Data Interchange: An Innovation Diffusion Perspective." Journal of Management Information Systems, Volume 11, Number 2, 1994, pp. 157-186.

Prescott, M. B., and Conger, S. A. "Information Technology Innovations: A Classification by IT Locus of Impact and Research Approach." Data Base Advances, Volume 26, Number 2 and 3, 1995, pp. 20-41.

Rogers, E. M. Diffusion of Innovations. Fourth ed. New York: The Free Press, 1995.

Star, S. L., and Ruhleder, K. "Steps toward an Ecology of Infrastructure: Design and Access for Large Information Spaces." Information Systems Research, Volume 7, Number 1, 1996, pp. 111-134.

Thirtle, C. G., and Ruttan, V. W. The Role of Demand and Supply in the Generation and Diffusion of Technical Change. Switzerland: Harwood Academic Publishers GmbH, 1987.

Tornatzky, L. G., and Klein, K. J. "Innovation Characteristics And AdoptionImplementation." IEEE Transactions on Engineering Management, Volume EM-29, Number 1, 1982, pp. 28-45.

Webster, J. "Networks of Collaboration or Conflict? Electronic Data Interchange and Power in the Supply Chain." Journal of Strategic Information Systems, Volume 4, Number 1, 1995, pp. 31-42.

Wolfe, R. A. "Organizational Innovation: Review, Critique and Suggested Research Directions." Journal of Management Studies, Volume 31, Number 3, 1994, pp. 405-431. 
Wrigley, C. D., Wagenaar, R. W., and Clarke, R. A. "Electronic Data Interchange in International trade: frameworks for the strategic analysis of ocean port communities." Journal of Strategic Information Systems, Volume 3, Number 3, 1994, pp. 211-234.

Zmud, R. W. "An examination of 'Push-Pull' theory applied to process innovation in knowledge work." Management Science, Volume 30, Number 6, 1984, pp. 727-738. 